\title{
Isotermas de adsorção de cádmio em solos ácricos ${ }^{1}$
}

\author{
Nivea M.P. Dias ${ }^{2}$, Luís R.F. Alleoni ${ }^{3}$, José C. Casagrande ${ }^{4}$ \& Otávio A. Camargo ${ }^{5}$
}

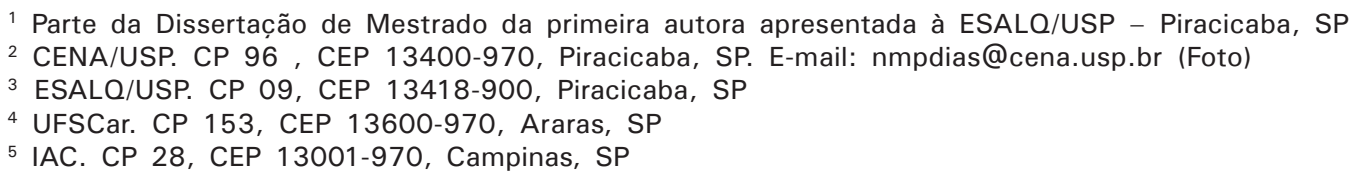

Protocolo $152-13 / 12 / 2000$

\begin{abstract}
Resumo: O cádmio é um metal pesado que pode ser adicionado ao solo via resíduos de pneus, óleos, disposição de lixo urbano, lodo de esgoto e fertilizantes fosfatados; é facilmente absorvido e translocado nas plantas e tem potencial de entrar na cadeia alimentar humana, causando sérios problemas de saúde, razão por que se objetivou, com este trabalho, estudar a adequação dos modelos de Langmuir e de Freundlich para descrever a adsorção do cádmio em amostras superficiais (O - 0,2 m) e subsuperficiais (horizonte B) de três solos do estado de São Paulo: Nitossolo Vermelho eutroférrico (NVef), Latossolo Vermelho acriférrico (LVwf) e Latossolo Amarelo ácrico (LAw). Para a determinação da quantidade de cádmio adsorvido, $20 \mathrm{~mL}$ de solução de $\mathrm{Ca}\left(\mathrm{NO}_{3}\right)_{2}$ $0,0025 \mathrm{~mol} \mathrm{~L}^{-1}$ com diferentes quantidades de cádmio $(5,10,15,25,50,75,100,125,150$, 175 e $200 \mathrm{mg} \mathrm{dm}^{-3}$ ) foram adicionados a $2 \mathrm{~g}$ de terra fina seca em estufa e agitados por $24 \mathrm{~h}$. Tanto o modelo de Langmuir como o de Freundlich se adequaram bem aos valores de cádmio adsorvido pelos solos. O Nitossolo Vermelho eutroférrico apresentou maiores valores de adsorção máxima de cádmio, obtidos pela isoterma de Langmuir, e os menores foram encontrados nos horizontes subsuperficiais dos Latossolos. Ambas as equações descreveram bem a adsorção de cádmio, principalmente quando as concentrações de cádmio adicionadas foram superiores a $50 \mathrm{mg} \mathrm{dm}^{-3}$.
\end{abstract}

Palavras-chave: cádmio, isotermas de adsorção, Langmuir, Freundlich

\section{Cadmium adsorption isotherms in acric oxisols}

\begin{abstract}
Cadmium is a heavy metal that may be added to the soils through tyre residues, oils, disposal of city wastes, sewage sludge and phosphatic fertilizers. It is easily absorbed and translocated in plants and has a great potential to enter in the human food chain, with serious problems to human health. The objective of this study was to evaluate Langmuir and Freundlich isotherms applied to cadmium adsorption on soils from the State of São Paulo, Brazil. Surface $(0-0.2 \mathrm{~m})$ and subsurface (B horizon) samples were taken from an Rhodic Kandiudalf (RK), an Anionic "Rhodic" Acrudox (RA) and an Anionic "Xanthic" Acrudox (XA). In order to quantify the adsorbed cadmium, $2 \mathrm{~g}$ of oven-dried soil were stirred in polyethylene tubes, for $24 \mathrm{~h}$, with $20 \mathrm{~mL}$ of a $\mathrm{Ca}\left(\mathrm{NO}_{3}\right)_{2} 0.0025 \mathrm{~mol} \mathrm{~L}^{-1}$ solution containing different quantities of cadmium $(5,10$, $15,25,50,75,100,125,150,175$ e $200 \mathrm{mg} \mathrm{dm}^{-3}$ ). Langmuir and Freundlich constants were estimated by nonlinear regressions. Cadmium adsorption was well described by both Langmuir and Freundlich models for all soils. RK exhibited the highest values of maximum cadmium adsorption, obtained from Langmuir isotherm, and the least values were from the subsurface layers of the Oxisols. Both equations described well the cadmium adsorption, mainly when the concentration of cadmium added was higher than $50 \mathrm{mg} \mathrm{dm}^{-3}$.
\end{abstract}

Key words: cadmium, adsorption isotherms, Langmuir, Freundlich

\section{INTRODUÇÃO}

O cádmio é considerado um metal pesado por apresentar número atômico 48 e massa específica $8,642 \mathrm{~g} \mathrm{~cm}^{-3}$; é, também, amplamente utilizado para revestimento de materiais, em pigmento de tintas e na indústria plástica, podendo ser adicionado ao solo por meio do lixo urbano ou industrial, lodo de esgoto e fertilizantes fosfatados; além disso, é facilmente absorvido e translocado nas plantas tendo potencial de entrar na cadeia alimentar humana, causando sérios problemas de saúde, como anemia, hipertensão, enfizema pulmonar, disfunções gástricas e intestinais. A persistência e a mobilidade de cádmio no solo são determinadas pela extensão de adsorção pelos colóides do solo. Os atributos do solo que 
mais influenciam a capacidade de adsorção de cádmio no solo, são os teores de matéria orgânica e de óxidos de $\mathrm{Fe}$ e $\mathrm{Al}$, a capacidade de troca de cátions, o pH, a força iônica da solução, a superfície específica e a mineralogia (King, 1988). Alguns pesquisadores estudaram o comportamento do cádmio em camadas superficiais de solos brasileiros, mas o conhecimento dos fatores que influenciam e/ou determinam seu comportamento ainda é restrito, principalmente em solos ácricos, que representam o extremo na escala de intemperização (Alleoni \& Camargo, 1994). No horizonte B desses solos, o valor do ponto de carga zero (PCZ) supera, em muitos casos, o do pH original, o que confere um balanço de carga positiva ao solo, que passa a atuar fundamentalmente como trocador de ânions. O fenômeno de reversão de carga ocorre quase sempre em profundidades maiores que $0,5 \mathrm{~m}$ pois, nesta condição, a matéria orgânica cujo PCZ é muito baixo (menor que 2) praticamente não atua. A maioria dos estudos com metais pesados, como o cádmio, restringe-se à camada arável dos solos $(0-0,2 \mathrm{~m})$; entretanto, é importante conhecer também o comportamento dos metais nas camadas mais profundas, em especial quando o horizonte $\mathrm{B}$ apresenta atributos eletroquímicos diferentes daqueles encontrados no horizonte A, como é o caso dos solos ácricos.

As isotermas de adsorção são equações matemáticas que descrevem as relações entre a quantidade de determinado elemento químico adsorvido e sua quantidade remanescente na solução de equilíbrio. As equações de Langmuir e Freundlich têm sido utilizadas com freqüência para descrever a adsorção de diferentes elementos químicos pela fase coloidal do solo, enquanto a equação de Langmuir, que foi inicialmente utilizada para descrever a adsorção de gases por sólidos, baseia-se nas suposições de que a superfície de adsorção é homogênea, isto é, a adsorção é constante e independente da extensão da cobertura da superfície; a adsorção ocorre em sítios específicos, sem interação com as moléculas do soluto, e a adsorção se torna máxima quando uma camada monomolecular cobre totalmente a superfície do adsorvente. Esta equação permite estimar-se o valor da constante relacionada à energia da ligação entre o elemento ou composto e a fase coloidal do solo, além de estimar sua adsorção máxima. Olsen \& Watanabe (1957) foram os primeiros pesquisadores a utilizarem a equação de Langmuir para descrever a adsorção de fosfato em solos. A partir daí, passou a ser amplamente utilizada para inúmeros cátions e ânions. Omae (1984) também obteve bons ajustes da equação de Langmuir aos dados de adsorção de cádmio. Pombo (1995) verificou que a adsorção de cádmio em solos do Rio Grande do Sul, em dois valores de $\mathrm{pH}$, ajustou-se à equação de Langmuir.

Outra equação utilizada para descrever a adsorção é a de Freundlich, na qual a energia de adsorção decresce logaritmamente, à medida que a superfície se vai tornando coberta pelo soluto, o que a diferencia da equação de Langmuir. Diversos autores utilizaram a equação de Freundlich para descrever a adsorção de cádmio em minerais e em solos (Petruzzelli et al.,1985; Hooda \& Alloway, 1994; Echeverria et al., 1998) e observaram bons ajustes aos dados de adsorção de cádmio.

O objetivo do presente trabalho foi estudar a adequação das equações de Langmuir e de Freundlich, para adsorção de cádmio em camadas superficiais e subsuperficiais de solos ácricos do Estado de São Paulo.

\section{MATERIAL E MÉTODOS}

Foram utilizadas amostras superficiais (0 - 0,2 m) e subsuperficiais, coletadas da camada de maior expressão do horizonte B de um Nitossolo Vermelho Eutroférrico (NVef) - "Rhodic Kandiudalf", um Latossolo Vermelho Acriférrico - Anionic "Rhodic" Acrudox (LVwf) e um Latossolo Amarelo Ácrico - Anionic "Xanthic" Acrudox (LAw) localizados na região norte do Estado de São Paulo, que correspondem, respectivamente, à Terra Roxa Estruturada, ao Latossolo Roxo ácrico e ao Latossolo variação Una ácrico na classificação vigente até 1999. O Nitossolo, cujo aspecto eletroquímico é diferente daquele dos Latossolos ácricos, por apresentar carga elétrica negativa líquida ao longo de todo o perfil, foi utilizado como referência. As análises químicas foram efetuadas segundo Camargo et al. (1986): o teor de carbono orgânico foi determinado após a oxidação da matéria orgânica do solo com solução de dicromato de potássio; os teores de óxidos $\left(\mathrm{Al}_{2} \mathrm{O}, \mathrm{SiO}_{2}\right.$ e $\mathrm{Fe}_{2} \mathrm{O}_{3}$ ) foram obtidos após ataque com ácido sulfúrico $(18 \mathrm{~N})$ enquanto ferro e o alumínio livres foram obtidos pela redução com ditionito de sódio e ferro e alumínio mal cristalizados foram quantificados após solubilização desses metais em ácido oxálico e seu sal de amônio. A retenção de cátions $(\mathrm{RC})$ corresponde à relação entre a $\mathrm{CTC}$ efetiva $(\mathrm{Ca}+\mathrm{Mg}+\mathrm{K}+\mathrm{Al})$ e a porcentagem de argila. A superfície específica (SE) foi determinada pelo método baseado na retenção do éter monoetílico do etilenoglicol (EMEG) (Cihacek \& Bremmer, 1979). O ponto de efeito salino nulo (PESN) foi obtido pela titulação com $\mathrm{H}^{+} \mathrm{e} \mathrm{OH}$ a três diferentes concentrações de $\mathrm{KCl}$, sendo o PESN o valor de $\mathrm{pH}$ no ponto de intersecção das curvas de titulação. A quantificação das cargas negativas permanente $\left(\sigma_{\mathrm{o}}\right)$ e variável $\left(\sigma_{\mathrm{H}}\right)$ seguiu o método preconizado por Anderson \& Sposito (1991) com base na maior seletividade do $\mathrm{Cs}+$ nas cavidades siloxanas dos argilominerais 2:1 que nas superfícies ionizáveis.

Para construção das curvas e obtenção dos parâmetros da equação de Langmuir $(\mathrm{x}=\mathrm{KC} \cdot \mathrm{b} /(1+\mathrm{KC}))$, sendo $\mathrm{x}$ - quantidade de cádmio adsorvido por unidade de massa de terra; c - concentração de cádmio na solução de equilíbrio; b - adsorção máxima e K - constante de afinidade) e da equação de Freundlich ( $\mathrm{x}=\mathrm{KC}^{\mathrm{b}} ; \mathrm{K}$ e b = parâmetros), foram tomados 2,0 g de terra ao $\mathrm{pH}$ natural, em duplicata, suspensos em $20 \mathrm{~mL}$ de solução $0,0025 \mathrm{~mol} \mathrm{~L}^{-1}$ de $\mathrm{Ca}\left(\mathrm{NO}_{3}\right)_{2}$ contendo cádmio como $\mathrm{Cd}\left(\mathrm{NO}_{3}\right)_{2}$ em concentrações variando de 5 a $200 \mathrm{mg} \mathrm{dm}^{-3}$ de cádmio. $\mathrm{O} \mathrm{pH}$ foi medido e, em seguida, as soluções centrifugadas e as determinações realizadas em triplicata. A quantidade de cádmio no extrato foi determinada por espectrofotometria de absorção atômica e o cádmio adsorvido pela fase coloidal do solo foi estimado por diferença do valor de cádmio em equilíbrio do cádmio adicionado. Posteriormente, utilizou-se o programa "Fitfun.bas" (Barrow, 1987) que ajusta equações não lineares aos resultados de adsorção, seguindo a metodologia dos "quadrados mínimos". Este método tem sido recomendado nos últimos anos, porque a linearização das equações induz a erros na análise de regressão e subseqüente erro na estimativa dos parâmetros dos modelos (Houng \& Lee, 1998). Harter (1984) examinou a linearização da equação original e concluiu que ela é inadequada, pois reduziu a variabilidade e sempre produziu 
um coeficiente de correlação significativo; observou, ainda, que a adsorção máxima estimada pela forma linear pode acarretar erro de até $50 \%$, ou mais, em estudos envolvendo baixas concentrações do metal.

As quantidades de cádmio adsorvido obtidas a partir dessas equações, foram comparadas às obtidas experimentalmente verificando-se, assim, a adequação dos modelos aos dados experimentais.

\section{RESULTADOS E DISCUSSÃO}

Tanto a CTC como a retenção de cátions (RC) dos Latossolos ácricos foram baixas. O NVef utilizado como comparação, apresentou resultados contrastantes, com altos valores de CTC e RC, tanto em superfície como em profundidade. Os maiores valores de $\mathrm{Ki}$ foram encontrados no NVef, cujo estado de intemperismo é menos avançado. Os valores de $\Delta \mathrm{pH}$ nos horizontes superficiais dos três solos estudados foram negativos devido, provavelmente, à contribuição da matéria orgânica, porém em subsuperfície os Latossolos ácricos apresentaram balanço positivo de carga. Esta reversão de carga no horizonte B é comum nesses solos, em virtude da predominância de óxidos e hidróxidos de ferro e alumínio e dos baixos teores de matéria orgânica. Os Latossolos ácricos apresentaram, em profundidade, valores de PESN acima do $\mathrm{pH}$ do solo.

No NVef os valores de cargas negativas variáveis $\left(\sigma_{H}\right)$ e permanentes $\left(\sigma_{0}\right)$ (Tabela 1 ) foram os mais altos, tanto em superfície como em profundidade, o que conferiu balanço de carga negativa em todo o perfil. Os valores de carga negativa variável $\left(\sigma_{\mathrm{H}}\right)$ encontrados nos solos, eram esperados, pois em solos tropicais os principais materiais responsáveis pela geração de cargas são a matéria orgânica, a caulinita e os óxidos e os hidróxidos de $\mathrm{Fe}$ e de $\mathrm{Al}$, que também possuem cargas variáveis. As quantidades de $\sigma_{\mathrm{H}}$ diminuíram em profundidade, o que pode ser atribuído ao menor teor de matéria orgânica, principal componente gerador de cargas negativas nos solos. A presença de carga elétrica negativa permanente, embora pequena, pode ser explicada pela presença de argilominerais do tipo 2:1 nos solos. A quantidade dessas cargas foi maior no NVef em relação ao Latossolos ácricos devido, provavelmente, ao seu menor grau de intemperização. De fato, nesse solo foram identificados, por difração de raios $\mathrm{X}$, minerais como clorita/vermiculita (intrestratificada) e vermiculita no horizonte A na fração argila, além de ilita e muscovita na fração silte no horizonte $B$ (resultados não apresentados) e minerais $1: 1$, como a caulinita.

Houve boa adequação das equações de Langmuir e de Freundlich aos dados de adsorção de cádmio (Figura 1) com altos coeficientes de determinação $\left(\mathrm{R}^{2}=0,99\right)$ o que concorda com ajustes observados por Omae (1984, 1986), Pombo (1995) e Echeverría et al. (1998).

O aumento na adsorção de cádmio nos Latossolos foi maior nas dosagens mais baixas e, a medida em que as dosagens adicionadas aumentaram, os incrementos foram menos acentuados. Este incremento pode ser observado pela relação percentual entre a quantidade de cádmio adsorvido e a quantidade adicionada inicialmente (Tabela 2). A maior porcentagem ocorreu nas menores dosagens adicionadas entre 0 e $25 \mathrm{mg} \mathrm{dm}^{-3}$, com média geral de $70 \%$; já a menor taxa de adsorção $(30 \%)$ foi encontrada para a dosagens mais elevada.

Tabela 2. Porcentagem de cádmio adsorvido nos solos, em função das dosagens de cádmio adicionado

\begin{tabular}{|c|c|c|c|c|c|c|}
\hline \multirow{3}{*}{$\begin{array}{c}\mathrm{Cd} \\
\mathrm{mg} \mathrm{dm}\end{array}$} & \multicolumn{2}{|c|}{ NVef } & \multicolumn{2}{|c|}{ LVwf } & \multicolumn{2}{|c|}{ LAw } \\
\hline & Sup & Prof & Sup & Prof & Sup & Prof \\
\hline & \multicolumn{6}{|c|}{$\%$} \\
\hline 5 & 96 & 94 & 72 & 58 & 86 & 72 \\
\hline 10 & 98 & 93 & 68 & 47 & 73 & 74 \\
\hline 15 & 99 & 94 & 68 & 47 & 74 & 69 \\
\hline 25 & 98 & 94 & 61 & 45 & 75 & 57 \\
\hline 50 & 98 & 90 & 53 & 36 & 68 & 49 \\
\hline 75 & 97 & 86 & 45 & 30 & 61 & 38 \\
\hline 100 & 97 & 83 & 42 & 28 & 59 & 31 \\
\hline 125 & 96 & 80 & 42 & 28 & 50 & 31 \\
\hline 150 & 96 & 77 & 36 & 25 & 48 & 31 \\
\hline 175 & 95 & 75 & 34 & 22 & 45 & 27 \\
\hline 200 & 94 & 73 & 37 & 24 & 43 & 28 \\
\hline
\end{tabular}

NVef - Nitossolo Vermelho eutroférrico; LVwf - Latossolo Vermelho acriférrico e LAw - Latossolo Amarelo ácrico

Os maiores valores percentuais de cádmio adsorvido em relação ao adicionado foram verificados no horizonte A do NVef, com média geral de $97 \%$, provavelmente por apresentar PESN inferior ao $\mathrm{pH}$ do solo, o que lhe conferiu carga líquida negativa proveniente de sua constituição mineralógica caulinítica e de argilominerais $2: 1$, juntamente com a presença de matéria orgânica nesta camada. Os menores valores

Tabela 1. Atributos químicos e mineralógicos dos solos estudados

\begin{tabular}{|c|c|c|c|c|c|c|c|c|c|c|c|c|c|}
\hline \multirow{2}{*}{ Hor } & \multirow{2}{*}{ PESN } & \multirow{2}{*}{$\mathrm{pH}$} & \multirow{2}{*}{$\Delta \mathrm{pH}$} & \multirow{2}{*}{$\mathrm{Ki}$} & $\sigma_{0}$ & $\sigma_{\mathrm{H}}$ & CTC & $\mathrm{RC}$ & $\mathrm{C}$ & Argila & $\mathrm{Ct}$ & $\mathrm{Fe}_{\mathrm{t}}$ & $\mathrm{Al}_{\mathrm{t}}$ \\
\hline & & & & & \multicolumn{4}{|c|}{$\mathrm{mmol}_{\mathrm{c}} \mathrm{kg}^{-1}$} & \multicolumn{5}{|c|}{$\mathrm{g} \mathrm{kg}^{-1}$} \\
\hline \multicolumn{14}{|c|}{ Nitossolo Vermelho eutroférrico } \\
\hline A & 3,6 & 5,6 & $-0,9$ & 1,42 & 30,2 & 63,1 & 167 & 131 & 26 & 820 & 249 & 298 & 183 \\
\hline $\mathrm{B}$ & 3,6 & 5,6 & $-0,7$ & 1,62 & 30,9 & 35,4 & 81 & 77 & 7 & 700 & 263 & 273 & 237 \\
\hline \multicolumn{14}{|c|}{ Latossolo Vermelho eutroférrico } \\
\hline A & 3,6 & 4,3 & $-0,9$ & 0,77 & 8,2 & 39,9 & 93 & 105 & 20 & 600 & 172 & 321 & 248 \\
\hline B & 5,6 & 4,9 & $+0,3$ & 0,75 & 4,7 & 16,1 & 22 & 13 & 5 & 640 & 216 & 338 & 257 \\
\hline \multicolumn{14}{|c|}{ Latossolo Amarelo ácrico } \\
\hline A & 3,4 & 4,3 & $-0,5$ & 0,78 & 8,4 & 32,3 & 43 & 38 & 16 & 350 & 248 & 59 & 113 \\
\hline B & 6,0 & 5,9 & $+0,6$ & 0,79 & 1,3 & 18,4 & 14 & 7 & 6 & 450 & 196 & 134 & 172 \\
\hline
\end{tabular}



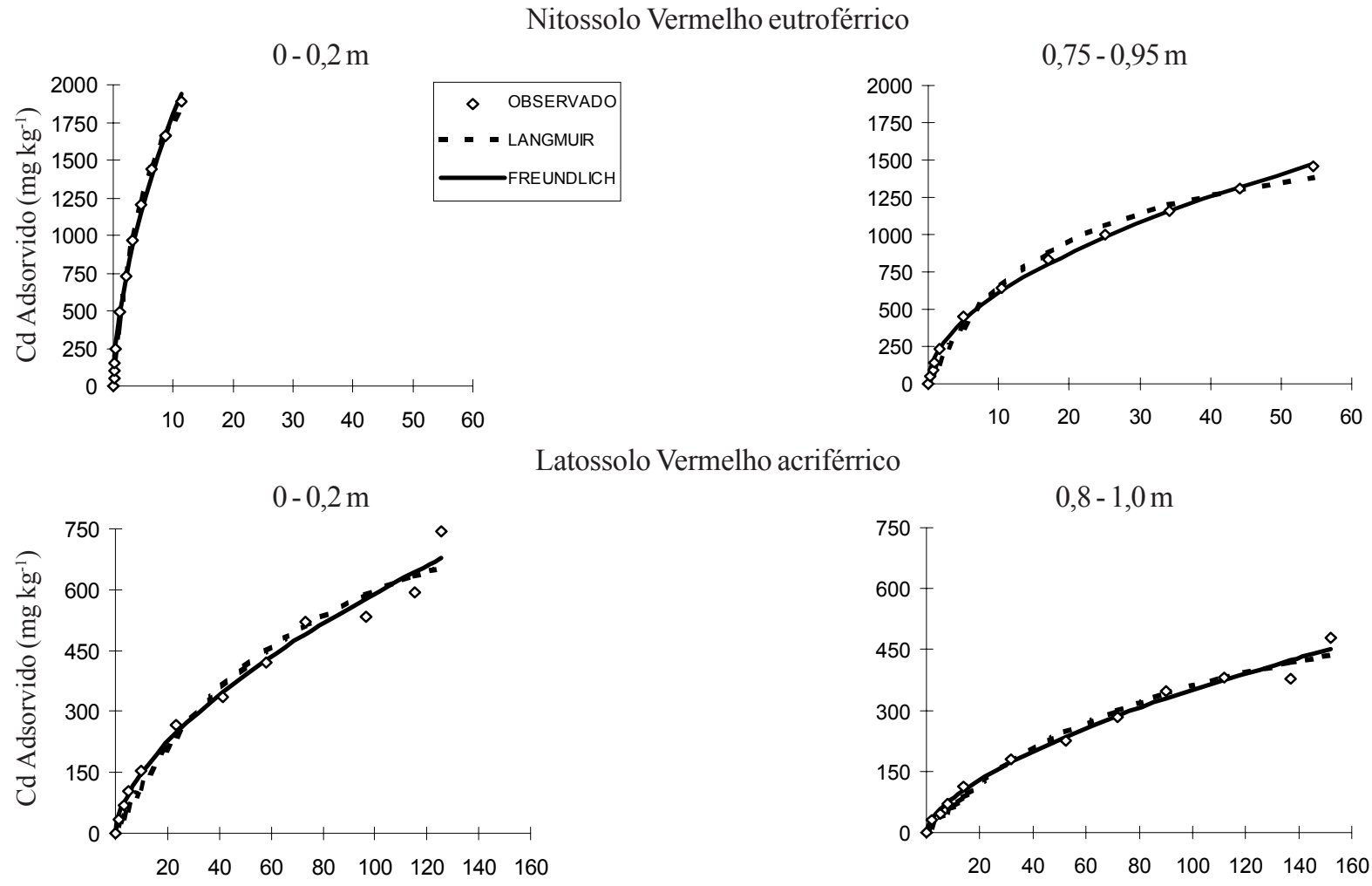

Latossolo Vermelho acriférrico

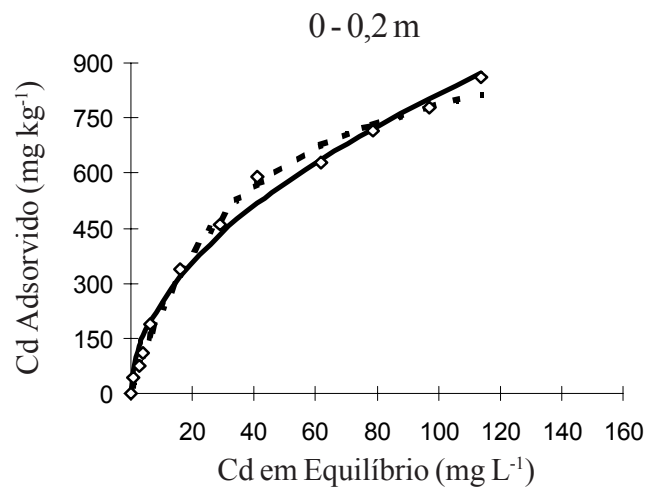

Latossolo Amarelo ácrico
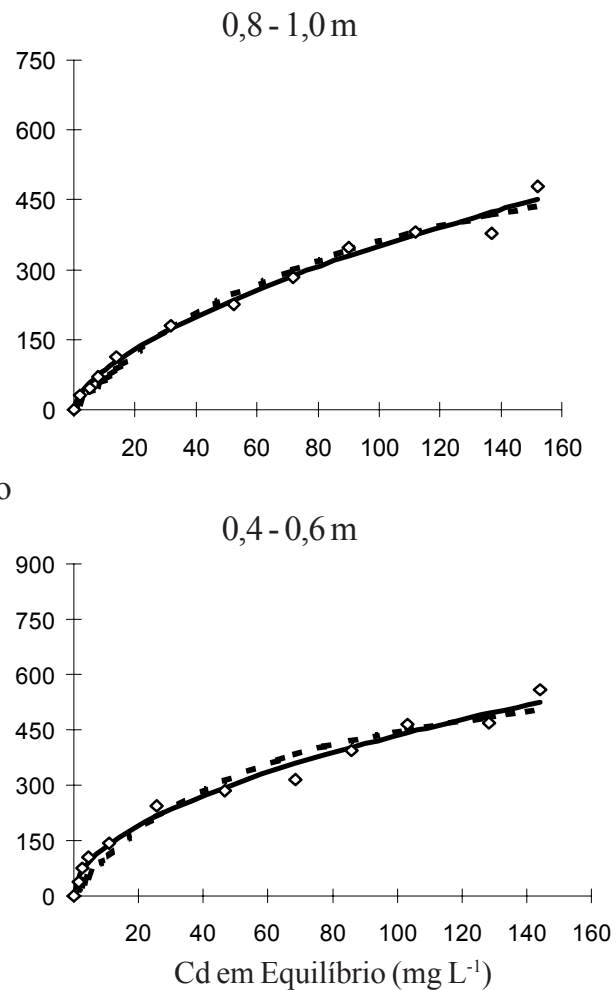

Figura 1. Curvas de adsorção de cádmio em camadas superficiais e subsuperficiais de diferentes solos

ocorreram no LVwf na camada subsuperficial, com $36 \%$, em média (Figura 1) o que pode ser explicado pelo balanço positivo de carga no horizonte $\mathrm{B}$, resultado do alto grau de intemperismo $\left(K_{i}=0,87\right)$ e maior participação de óxidos de ferro e alumínio na definição das cargas.

O Nitossolo Vermelho eutroférrico apresentou, na camada superficial e em todas as dosagens adicionadas, adsorção em torno de $100 \%$, o que realça sua alta afinidade pelo elemento (Figura 1) com curva tipo H (High) (Sposito, 1982). Este fenômeno é resultado de forte interação específica entre as partículas do solo e o cádmio (Neal \& Sposito, 1986). Em profundidade, nas dosagens mais baixas o NVef adsorveu $90 \%$ da quantidade aplicada, chegando a $70 \%$, na dosagem mais elevada.

Em ambas as profundidades, os Latossolos e o Nitossolo apresentaram, na camada subsuperficial, curva tipo L (L = Langmuir) caracterizada por um decréscimo na inclinação da curva, à medida que os sítios disponíveis para a adsorção vão diminuindo, devido ao recobrimento da superfície adsorvedora e indica que, em baixas concentrações, a superfície tem alta afinidade pela substância adsorvida, sendo que esta afinidade diminui em maiores concentrações. Curvas tipo L para adsorção de cádmio são reportadas por Pombo (1995).

As duas equações se adequaram melhor nas concentrações superiores a $50 \mathrm{mg} \mathrm{dm}^{-3}$, sendo que, a partir desta concentração, os dois modelos foram hábeis para descrever a adsorção de cádmio nos solos estudados. Resultados semelhantes foram obtidos por Omae (1986) em solos do Estado de São Paulo, e o autor observou que na faixa de concentração entre $1 \mathrm{e} 10 \mathrm{mg} \mathrm{dm}^{-3}$, tanto a equação de Langmuir como a de Freundlich não foram precisas na descrição do fenômeno. No LVwf em superfície e em profundidade, a equação de Freundlich se adequou melhor às baixas concentrações, inferiores a $50 \mathrm{mg} \mathrm{dm}^{-3}$, enquanto no LAw, a equação de Langmuir nas menores concentrações, descreveu melhor a adsorção; já em profundidade, a equação de Freundlich adequou-se melhor, porém no NVef a equação de Langmuir, na menor concentração, se adequou melhor tanto em superfície como em profundidade; enfim, a equação de Freundlich não descreveu bem a adsorção de $\mathrm{Cd}$ nesse solo, 
que apresentou alta capacidade de adsorção do elemento, o que pode ser observado também no LAw, em superfície, que apresentou alta capacidade de adsorção, vindo logo depois do NVef.

O NVef apresentou maiores valores de adsorção máxima (b) obtidos na isoterma de Langmuir e constante de afinidade $(\mathrm{K})$ obtidos pelas equações de Langmuir e de Freundlich, tanto em superfície como em profundidade (Tabela 3) provavelmente por possuir PESN inferior ao $\mathrm{pH}$ do solo, o que lhe confere carga líquida negativa em todo o perfil $(\Delta \mathrm{pH}=\mathrm{-}$ 0,9 em superfície e - 0,7 em subsuperfície) provenientes de sua constituição mineralógica, com predominância de caulinítica e de argilominerais 2:1, o que mostra seu menor estado de intemperização $(\mathrm{Ki}=1,74)$ em relação aos Latossolos (Tabela 1).

Tabela 3. Constantes de Langmuir e de Freundlich, obtidas a partir dos resultados de adsorção de cádmio para os solos estudados

\begin{tabular}{|c|c|c|c|c|c|}
\hline \multirow[b]{2}{*}{ Solo } & \multirow[b]{2}{*}{ Camada } & \multicolumn{2}{|c|}{ Langmuir } & \multicolumn{2}{|c|}{ Freundlich } \\
\hline & & $\begin{array}{c}\mathrm{K} \\
\mathrm{dm}^{3} \mathrm{mg}^{-1}\end{array}$ & $\begin{array}{c}\mathrm{b} \\
\mathrm{mg} \mathrm{kg}^{-1}\end{array}$ & $\mathrm{~K}$ & $\mathrm{~N}$ \\
\hline \multirow[t]{2}{*}{ NVef } & Sup. & 0,17 & 2495 & 468,63 & 0,59 \\
\hline & Prof. & 0,05 & 1877 & 184,07 & 0,52 \\
\hline \multirow[t]{2}{*}{ LVwf } & Sup. & 0,01 & 1086 & 37,55 & 0,60 \\
\hline & Prof. & 0,01 & 727 & 20,93 & 0,61 \\
\hline \multirow[t]{2}{*}{ LAw } & Sup. & 0,03 & 1073 & 77,36 & 0,51 \\
\hline & Prof. & 0,02 & 707 & 40,79 & 0,51 \\
\hline
\end{tabular}

Os menores valores de "b" e "K" encontrados nos horizontes subsuperficiais dos Latossolos (Tabela 3) podem ser explicados pelo balanço de carga positivo no horizonte B, como resultado do alto grau de intemperismo $(\mathrm{Ki}=0,87$ no $\mathrm{LVwf}$ e $\mathrm{Ki}=0,97$ no LAw) (Tabela 1 ) e maior participação dos óxidos de ferro e de alumínio na definiç̧ão das cargas. Como os valores de PESN desses óxidos são altos (variando de 6,5 a 8,5) quanto maiores suas quantidades, maior a possibilidade de o PESN dos solos ser maior que seus valores de $\mathrm{pH}$, caso em que ocorre redução na adsorção do elemento. Esses resultados estão de acordo com os encontrados por Naidu et al. (1994) que utilizaram a equação de Freundlich para descrever a adsorção de cádmio em solos com diferentes constituições mineralógicas. Os autores encontraram os menores valores de cádmio adsorvido nos solos altamente intemperizados e relataram que esta menor adsorção pode ser atribuída à alta superfície de carga positiva e à baixa densidade de carga negativa, provenientes das mineralogias oxídicas e alofânicas dos solos.

Em pH menor que 6,5, a magnitude da adsorção é controlada pela capacidade de troca de cátions isolada de cada constituinte do solo (Zachara et al., 1992). Em vista de todos os solos estudados apresentarem valores de $\mathrm{pH}$ inferiores a 6,5, constatou-se este fato no presente trabalho, sendo que o NVef apresentou maior quantidade de caulinita e maior CTC e com mais de um tipo de mineral 2:1. Como conseqüência, apresentou maior constante de afinidade $(\mathrm{K})$ da equação de Freundlich e adsorção máxima (b) da equação de Langmuir.

As maiores adsorções (b) foram encontradas na camada superficial devido, provavelmente, ao maior teor de carbono orgânico em todos os solos. Maiores valores de "b" da equação de Langmuir e "K" da equação de Freundlich também foram encontrados por Echeverria et al. (1998) em solos com altos conteúdos de matéria orgânica. Os autores relatam que a matéria orgânica favoreceu a retenção de cádmio. Petruzzelli et al. (1985), Hooda \& Alloway (1994) e Gray et al. (1998) também encontraram altos valores de $\mathrm{K}$ da equação de Freundlich, os quais também estiveram relacionados a altos teores de carbono orgânico dos solos. A matéria orgânica foi, sem dúvida, o principal sítio de adsorção de cádmio, principalmente em seus grupos carboxílicos e fenólicos. Na camada superficial do LAw, onde o teor de carbono foi 2,7 vezes mais alto que no horizonte $\mathrm{B}$, a adsorção máxima de $\mathrm{Cd}$ foi $52 \%$ maior. No NVef, a diferença também foi alta, em torno de $33 \%$ em favor do horizonte A, sendo que a queda do teor de carbono em profundidade foi de 3,7 vezes.

\section{CONCLUSÕES}

1. Tanto o modelo de Langmuir como o de Freundlich se adequaram bem aos valores de cádmio adsorvido pelos solos, principalmente nas concentrações superiores a $50 \mathrm{mg} \mathrm{dm}^{-3}$.

2. O Nitossolo Vermelho eutroférrico apresentou maiores valores de adsorção máxima, obtidos pela isoterma de Langmuir e os menores valores foram encontrados nos horizontes subsuperficiais dos Latossolos.

\section{AGRADECIMENTOS}

À Fundação de Amparo à Pesquisa do Estado de São Paulo (FAPESP) pela concessão de bolsa à primeira autora, durante a execução deste projeto de pesquisa.

\section{LITERATURA CITADA}

Alleoni, L.R.F.; Camargo, O.A. Ponto de efeito salino nulo de Latossolos ácricos. Revista Brasileira de Ciência do Solo, Campinas, v.18, p.175-180, 1994.

Anderson, S.J.; Sposito, G. Cesium-adsorption method for measuring accessible structural surface charge. Soil Science Society of America Journal, Madison, v.55, p.1569-1576, 1991. Barrow, N.J. Reactions with variable-charge soils. Dordrecht: Martinus Nijhoff Publishers, 1987. 191p.

Camargo, O.A.; Moniz, A.C.; Jorge, J.A.; Valadares, J.M.A.S. Métodos de análise química, mineralógica e física de solos do Instituto Agronômico de Campinas. Campinas: IAC, 1986. 94p.

Cihacek, J.L.; Bremmer, J.M. A simplified ethylene glycol monoethyl ether procedure for assessment of soil surface area. Soil Science Society of America Journal, Madison, v.43, p.21-22, 1979.

Echeverria, J.C.; Morera, M.T.; Mazkiaran, C. Competitive sorption of heavy metal by soils. Isotherms and fractional factorial experiments. Environmental Pollution, New York, v.101, p.275-284, 1998.

Gray, C.W.; McLaren, R.G.; Roberts, A.H.C.; Condron, L.M. Sorption de cadmium from some New Zealand soils: Effect of $\mathrm{pH}$ and contact time. Australian Journal of Soil Research, Melbourne, v.36, p.199-216, 1998. 
Harter, R.D. Curve-fit errors in Langmuir adsorption maximum. Soil Science Society of America Journal, Madison, v.48, p.749-752, 1984.

Hooda, P.S.; Alloway, B.J. Effects of time and temperature on the bioavailability of $\mathrm{Cd}$ and $\mathrm{Pb}$ from sludge-amended soils. Journal of Soil Science, Oxford, v.44, p.97-110, 1994.

Houng, K.H.; Lee,Y.D, Comparisons of linear and nonlinear Langmuir end Freundlich curve-fit in the study of $\mathrm{Cu}, \mathrm{Cd}$, and $\mathrm{Pb}$ adsorption on Taiwan soils. Soil Science, Baltimore, v.163,p.115-121,1998.

King, L.D. Retention of metals by several soils of the Southeastern United States. Journal of Environmental Quality, Madison, v.17, p.239-246, 1988.

Naidu, R.; Bolan, N.S.; Kookana, R.S.; Tiller, K.G. Ionic-strength and $\mathrm{pH}$ effects on the sorption of cadmium and surface charge of soils. European Journal of Soil Science. Oxford, v.45, p.419-429, 1994.

Neal, R.H.; Sposito, G. Effects of soluble organic matter and sewage sludge amendments on cadmium sorption by soils at low cadmium concentration. Journal of Environmental Quality, Madison, v.142, p.164-172, 1986.

Olsen, S.R.; Watanabe, F.S. A method to determine a phosphorus adsorption maximum of soil as measured by the Langmuir isotherm. Soil Science Society of America Proceedings, Madison, v.21, p.144-149, 1957.
Omae, S. Adsorção de cádmio em solo podzólico vermelhoamarelo orto, glei húmico da região do Vale do Ribeira, $\mathrm{SP}$, e terra roxa estruturada, do município de Piracicaba, SP. Piracicaba: ESALQ/USP. 1984. 41p. Dissertação Mestrado

Omae, S. Adsorção e deslocamento dos metais pesados, cromo, chumbo e cádmio em alguns solos do Estado de São Paulo. Piracicaba: ESALQ/USP. 1986. 184p. Tese Doutorado

Petruzzelli, G.; Guidi, G.; Lubrano, L. Ionic strength effect on heavy metal adsorption by soil. Communications in Soil Science and Plant Analysis, New York, v.16, p.971-986, 1985.

Pombo, L.C.A. Sorção de cádmio em solos do Estado do Rio Grande do Sul. Revista Brasileira de Ciência do Solo, Campinas, v.19, p.19-24, 1995.

Sposito, G. The use of the Langmuir equation in the interpretation of "adsorption" phenomena. II The "two surface" Langmuir equation. Soil Science Society of America Journal, Madison, v.46, p.1174-1182, 1982.

Zachara, J.M.; Smith, S.C.; Resch, C.T.; Cowan, C.E. Cadmium sorption to soil separates containing layer silicates and iron and aluminum oxides. Soil Science Society of America Journal, Madison, v.56, p.1974-1084, 1992. 